\title{
Histamine regulates cytokine production in maturing dendritic cells, resulting in altered $T$ cell polarization
}

\author{
Alessandra Mazzoni, ${ }_{1}^{1}$ Howard A. Young, ${ }^{2}$ Jessica H. Spitzer, ${ }^{1}$ Alberto Visintin, ${ }^{1}$ \\ and David M. Segal ${ }^{1}$
}

${ }^{1}$ Experimental Immunology Branch, National Cancer Institute, Bethesda, Maryland, USA

${ }^{2}$ Laboratory of Experimental Immunology, National Cancer Institute, Frederick, Maryland, USA

Address correspondence to: David Segal, Building 10, Room 4B36, NIH, Bethesda, Maryland 20892-1360, USA. Phone: (301) 496-3109; Fax: (301) 496-0887; E-mail: dave_segal@nih.gov.

Received for publication August 8, 2001, and accepted in revised form October 18, 2001.

\begin{abstract}
Atopic diseases such as allergy and asthma are characterized by increases in Th2 cells and serum IgE antibodies. The binding of allergens to IgE on mast cells triggers the release of several mediators, of which histamine is the most prevalent. Here we show that histamine, together with a maturation signal, acts directly upon immature dendritic cells (iDCs), profoundly altering their $\mathrm{T}$ cell polarizing capacity. We demonstrate that iDCs express two active histamine receptors, $\mathrm{H} 1$ and $\mathrm{H} 2$. Histamine did not significantly affect the LPS-driven maturation of iDCs with regard to phenotypic changes or capacity to prime naive $T$ cells, but it dramatically altered the repertoire of cytokines and chemokines secreted by mature DCs. In particular, histamine, acting upon the $\mathrm{H} 2$ receptor for a short period of time, increased IL-10 production and reduced IL-12 secretion. As a result, histamine-matured DCs polarized naive $\mathrm{CD} 4^{+} \mathrm{T}$ cells toward a Th2 phenotype, as compared with DCs that had matured in the absence of histamine. We propose that the Th2 cells favor IgE production, leading to increased histamine secretion by mast cells, thus creating a positive feedback loop that could contribute to the severity of atopic diseases.
\end{abstract}

J. Clin. Invest. 108:1865-1873 (2001). DOI:10.1172/JCI200113930.

\section{Introduction}

Naive $\mathrm{CD} 4^{+} \mathrm{T}$ cells differentiate into Th1 or Th2 subsets, characterized by the release of distinct patterns of cytokines. Th 1 cells produce IFN- $\gamma$ and TNF- $\beta$, which promote cell-mediated immunity, while Th2 cells secrete IL-4, IL-5, IL-6, IL-9, IL-10, and IL-13, which favor humoral responses (1). The polarization of naive $\mathrm{T}$ cells toward Th1 or Th2 phenotypes is mediated primarily by dendritic cells (DCs). Peripheral tissues are populated by immature DCs (iDCs), highly endocytic cells that are well adapted for the capture of antigens, but are inefficient antigen-presenting cells (APCs). Upon encountering microbial products or inflammatory cytokines, iDCs reduce antigen $(\mathrm{Ag})$ uptake, migrate to the draining lymph nodes, and upregulate surface expression of MHC, adhesion, and costimulatory molecules. In this mature state, DCs are potent APCs that display a unique capacity for activating and polarizing naive T cells (2-4). Although distinct DC subsets with different Th-inducing potentials have been described (5-7), DCs also display functional plasticity, and can be instructed to polarize $\mathrm{T}$ cells by inflammatory mediators that are present in the peripheral microenvironment. These mediators control the production of cytokines by mature DCs (mDCs) after they have migrated to the draining lymph nodes (8). For example, iDCs that are exposed in the periphery to both a maturation stimulus and IFN- $\gamma$ produce high amounts of IL-12, a crucial factor in the induction of
Th1 responses, when they reach the lymphoid organs $(9,10)$. Conversely, the presence of prostaglandin E2 or IL-10 at a site of inflammation results in mDCs that have both a reduced capacity to release IL-12 and a tendency toward Th2 polarization (11-15). The levels of DC-derived IL-12 are instrumental in the Th1-Th2 balance, but additional factors, including the strength and duration of antigenic stimulation or the nature of costimulatory molecules, might also be involved (16-19).

Mast cells, the primary effectors of immediate-type allergic reactions, reside in peripheral tissues that directly interface with the external environment (20). Crosslinking of surface IgE by cognate antigens, or direct binding of microbial products or complement components to cellular receptors, induces mast cells to release large amounts of inflammatory mediators such as histamine, proteases, prostaglandins, and leukotrienes. In addition, activated mast cells produce a number of cytokines, including TNF- $\alpha$, GM-CSF, IL-3, IL-4, IL-5, IL-6, IL-10, and IL-13, that have the potential to influence $\mathrm{T}$ cell and $\mathrm{B}$ cell responses; IL-4, in particular, strongly favors Th2 formation. Because mast cells have the capacity to process and present antigens to both $\mathrm{CD}^{+}$and $\mathrm{CD}^{+} \mathrm{T}$ cells in vitro, it was speculated that they might play an important role in activating and polarizing $T$ cells in vivo $(21,22)$. However, this hypothesis seems unlikely, because mast cells reside in anatomical compartments that are distinct from those populated by naive $T$ cells. On the other hand, both 
mast cells and iDCs are located in the periphery, often in close proximity to each other. Therefore, we reasoned that mast cell-derived mediators might influence $T$ cell polarization by acting on DCs. Among these mediators, histamine, which accounts for about $10 \%$ of mast cell granule content, seemed an attractive candidate as a DC instructor, because previous reports showed that it could inhibit IL-12 secretion from monocytes that had been stimulated with bacterial products such as LPS or Staphylococcus aureus Cowon strain 1 (SAC) $(23,24)$. We therefore analyzed the effect of histamine on the LPSdriven maturation of DCs, and found that it profoundly alters both the cytokines that DCs express and the capacity of these cells to polarize naive $\mathrm{T}$ cells. These findings potentially provide an explanation for the elevated levels of Th2 cells and IgE that are frequently observed in atopic individuals.

\section{Methods}

Cells. Human monocyte-derived iDCs were generated by culturing elutriated monocytes (collected from healthy NIH Blood Bank donors) for 6-8 days in medium containing GM-CSF and IL-4, as described (25). The cultures always contained more than 95\% iDCs, based upon analyses of CD1a, CD14, and CD3 surface expression. mDCs were prepared by treating iDCs $\left(1 \times 10^{6} / \mathrm{ml}\right)$ with $100 \mathrm{ng} / \mathrm{ml}$ (unless stated otherwise) LPS (from Salmonella minnesota; Sigma Chemical Co., St. Louis, Missouri, USA) in the presence or absence of $10 \mu \mathrm{M}$ (unless stated otherwise) histamine (Sigma Chemical Co.) overnight at $37^{\circ} \mathrm{C}$. In some experiments, iDCs were incubated for 1 hour at $37^{\circ} \mathrm{C}$ with the histamine receptor antagonists pyrilamine $\left(K_{\mathrm{d}}=0.4 \mathrm{nM}\right)$, cimetidine $\left(K_{\mathrm{d}}=900 \mathrm{nM}\right)$, and thioperamide $\left(K_{\mathrm{d}}=4\right.$ $\mathrm{nM}$ ), (all from Sigma Chemical Co.), for H1, H2, and $\mathrm{H} 3$, respectively (26). iDCs were then stimulated with LPS and histamine. Supernatants from DC cultures were either stored at $-20^{\circ} \mathrm{C}$ or assayed immediately for cytokine content. CD45RA ${ }^{+}, \mathrm{CD}^{+}{ }^{+}$naive $\mathrm{T}$ cells were obtained from PBMCs of healthy NIH Blood Bank donors by negative selection with a Naive T Cell Column Kit (R\&D Systems Inc., Minneapolis, Minnesota, USA); purity of cells was always greater than $95 \%$.

Cytokine assays. Human IL-12 p70 was measured by using DuoSet ELISA Development Kits, following the manufacturer's instructions (R\&D Systems Inc.). The detection limit was $10 \mathrm{pg} / \mathrm{ml}$. ELISA kits for human IL-10 (Endogen Inc., Woburn, Massachusetts, USA) had a detection limit of $3 \mathrm{pg} / \mathrm{ml}$. The polyclonal neutralizing goat anti-human IL-10 antibody and its isotype-matched control goat IgG were from R\&D Systems Inc., and were used at $50 \mu \mathrm{g} / \mathrm{ml}$.

Calcium flux. Cytoplasmic $\mathrm{Ca}^{2+}$ was measured by flow cytometry using the fluo-3 AM fluorescent calcium marker (Molecular Probes Inc., Eugene, Oregon, USA), as described (27). Briefly, DCs were washed with HBSS and loaded for 30 minutes at room temperature with 4 $\mu \mathrm{M}$ fluo-3 AM in the presence of $0.06 \%$ Pluronic F-127 (Molecular Probes Inc.). Cells were diluted fivefold in
HBSS containing $1 \%$ FCS, incubated for 30 minutes at room temperature, washed three times, and kept at $4^{\circ} \mathrm{C}$ in HEPES-buffered saline $(137 \mathrm{mM} \mathrm{NaCl}, 5 \mathrm{mM}$ $\mathrm{KCl}, 1 \mathrm{mM} \mathrm{Na}_{2} \mathrm{HPO}_{4}, 5 \mathrm{mM}$ glucose, $1 \mathrm{mM} \mathrm{CaCl} 2,0.5$ $\mathrm{mM} \mathrm{MgCl}_{2}, 1 \mathrm{mg} / \mathrm{ml} \mathrm{BSA}$, and $10 \mathrm{mM}$ HEPES, $\mathrm{pH}$ 7.4). Five minutes before FACS analysis, the fluo-3-labeled cells were warmed to $37^{\circ} \mathrm{C}$. Proper loading was checked by treating cells with $2 \mu \mathrm{g} / \mathrm{ml}$ of ionomycin.

Mixed lymphocyte reactions. Mixed lymphocyte reactions were performed as described (28). Briefly, DCs that had been treated with the indicated stimuli were washed, irradiated (25 Gy), and added as stimulator cells to 96 -well plates containing $5 \times 10^{4}$ responder cells per well. Responder cells were allogeneic naive $\mathrm{CD}^{2} 5 \mathrm{RA}^{+}, \mathrm{CD}^{+} \mathrm{T}$ cells. After 4 days of stimulation, cells were pulsed with $5 \mu \mathrm{Ci} / \mathrm{ml}$ of $\left[{ }^{3} \mathrm{H}\right]$ thymidine (NEN Life Science Products Inc., Boston, Massachusetts, USA) for 16 hours and harvested. Incorporation of $\left[{ }^{3} \mathrm{H}\right]$ thymidine was measured by scintillation counting. Data are expressed as cpm (mean $\pm \mathrm{SE}$ ) of duplicate cultures. For polarization studies, $2.5 \times 10^{5}$ naive $\mathrm{CD}^{+} \mathrm{T}$ cells were cocultured in complete medium with irradiated DCs at a 1:10 stimulator to responder ratio. After 4 days, cells were split and expanded for 7-10 days in complete medium supplemented with $50 \mathrm{U} / \mathrm{ml}$ recombinant human IL-2 (Hoffman-LaRoche Inc., Nutley, New Jersey, USA), after which they were internally labeled for cytokine production (see below).

Flow cytometry. Cell surface staining was performed using the following monoclonal antibodies from PharMingen (San Diego, California, USA): antiCD14 ${ }^{\mathrm{PE}}$, anti-CD1 $\mathrm{a}^{\mathrm{PE}}$, anti-CD80 ${ }^{\mathrm{PE}}$, anti-CD86 ${ }^{\mathrm{FITC}}$, anti-HLA-DR ${ }^{\mathrm{FITC}}$, anti-CD83 ${ }^{\mathrm{PE}}$, and anti-CD40 ${ }^{\mathrm{PE}}$. Anti-MHC IFTC (W6/32) was prepared in this laboratory. Staining was performed in the presence of 100 $\mu \mathrm{g} / \mathrm{ml}$ nonimmune human IgG, to block binding to Fc $\gamma$ R. Ten thousand cells were acquired for each sample, and dead cells were gated out based on their lightscattering properties. Intracellular staining for cytokines was performed on T cells after IL-2 expansion. T cells $\left(1 \times 10^{6} / \mathrm{ml}\right)$ were stimulated with $10 \mathrm{ng} / \mathrm{ml}$ PMA and $1 \mu \mathrm{g} / \mathrm{ml}$ ionomycin for 4 hours. Brefeldin A $(10 \mu \mathrm{g} / \mathrm{ml})$ was added during the last 2 hours of culture, to prevent cytokine secretion. Cells were fixed and permeabilized using a commercial kit (PharMingen), and intracellular cytokines were detected with FITC/anti-IFN- $\gamma$ and PE/anti-IL-4 (PharMingen). Thirty thousand events were acquired for each sample.

RT-PCR. Total RNA was isolated from iDCs using TRIzol (Life Technologies Inc., Rockville, Maryland, USA) according to the manufacturer's instructions. cDNA was synthesized from $2 \mu \mathrm{g}$ of total RNA using a SuperScript II reverse transcriptase extension kit (Life Technologies Inc.), and amplified using $200 \mathrm{ng}$ of cDNA, with primers complementary to the published sequences of the three histamine receptors, $\mathrm{H} 1, \mathrm{H} 2$, and H3 (29), or GAPDH (Clontech Laboratories Inc., Palo Alto, California, USA), and a Taq polymerase PCR kit (Life Technologies Inc.). Thirty-five cycles were per- 
formed ( 1 minute at $94^{\circ} \mathrm{C}$ for denaturation, 1 minute at $55^{\circ} \mathrm{C}$ for annealing, and 1 minute at $72^{\circ} \mathrm{C}$ for extension). After amplification, portions of the PCR products were electrophoresed on a $1 \%$ agarose gel and visualized using ethidium bromide. Controls in which the reverse transcription step was omitted confirmed that the PCR products reflected messenger RNA levels, and not contaminating genomic DNA.

$R$ Nase protection assays. Multiprobe RNase protection assays (RPAs) were performed according to the manufacturer's directions (PharMingen) with some modifications. For hybridization, probes were synthesized with [ $\left.{ }^{33} \mathrm{P}\right] \mathrm{UTP}(70-80 \mu \mathrm{Ci} /$ reaction) using a PharMingen In Vitro Transcription Kit. Yeast tRNA and EDTA were then added according to the manufacturer's instructions, and the probe was purified on a G25 Microspin column (Amersham-Pharmacia Biotech, Piscataway, New Jersey, USA) by centrifuging for 2 minutes at $1,000 \mathrm{~g}$. Probe $\left(0.5 \times 10^{6}\right.$ to $\left.1.0 \times 10^{6} \mathrm{cpm}\right)$ was added to each RNA sample in a final hybridization volume of 10-20 $\mu \mathrm{l}$, containing at least 50\% PharMingen hybridization buffer. For RNase inactivation, a master cocktail containing $200 \mu \mathrm{l}$ Ambion RNase inactivation reagent (Ambion Inc., Austin, Texas, USA), $50 \mu \mathrm{l}$ ethanol, $5 \mu \mathrm{g}$ yeast tRNA, and $1 \mu \mathrm{l}$ Ambion GycoBlue coprecipitate (Ambion Inc.) per RNA sample was used to precipitate the protected RNA. After adding the individual $\mathrm{RNase}$-treated samples to $250 \mu \mathrm{l}$ of the cocktail, the samples were mixed, placed at $-70^{\circ} \mathrm{C}$ for $30 \mathrm{~min}$ utes, and centrifuged at $16,000 \mathrm{~g}$ for 15 minutes in a room-temperature microcentrifuge. The supernatants were decanted, a sterile cotton swab was used to remove excess liquid, and the pellet was resuspended in $3 \mu \mathrm{l}$ of PharMingen sample buffer. After electrophoresis, dried gels were exposed to Kodak BioMax film for 1-7 days at $-70^{\circ} \mathrm{C}$. X-ray films were scanned and band intensities quantitated using TotalLab software (Nonlinear Dynamics, Newcastle upon Tyne, United Kingdom).

\section{Results}

Immature human DCs express histamine receptors. Histamine signaling is mediated through three surface receptors: $\mathrm{H} 1, \mathrm{H} 2$, and $\mathrm{H} 3$ (26). Since it is not known which histamine receptors, if any, are expressed by DCs, we used RT-PCR to detect receptor message in RNA extracted from human monocyte-derived iDCs. Figure1a shows that iDCs from three different donors express high levels of $\mathrm{H} 1$ and $\mathrm{H} 2$, and lower, variable amounts of $\mathrm{H3}$; the three histamine receptors were also expressed in mDCs (data not shown). H1 is known to induce an increase in cytoplasmic $\mathrm{Ca}^{2+}$ upon binding histamine. To determine whether $\mathrm{H} 1$ message produced a functional receptor, fluo-3-loaded iDCs, either untreated or preincubated with antagonists specific for each individual histamine receptor, were stimulated with histamine, and intracellular calcium fluxes were followed over time by flow cytometry. As shown in Figure $1 \mathrm{~b}$, histamine induced a rapid calcium mobilization, which was specifically abolished by pretreatment with the $\mathrm{H} 1$ antagonist. Experiments presented below (see Figure $3 \mathrm{~b}$ ) indicate that $\mathrm{H} 2$ receptors are also functional in iDCs. We conclude that iDCs and mDCs express $\mathrm{H} 1, \mathrm{H} 2$, and $\mathrm{H} 3$ histamine receptors, and that $\mathrm{H} 1$ and $\mathrm{H} 2$ are active in iDCs.

Minor effects of histamine on phenotype and stimulatory capacity of $D C s$. We next tested whether histamine, either alone or in combination with LPS, has any effect on the maturation of DCs. A histamine concentration of 10 $\mu \mathrm{M}$ was used because it is within the range of concentration $(2-20 \mu \mathrm{M})$ of histamine detected in nasal secretions and bronchoalveolar lavages from allergic patients following antigenic challenge (30-32). iDCs were stimulated with LPS in the presence or absence of histamine for 18-24 hours, and then analyzed for surface expression of maturation markers and for the ability to prime naive $\mathrm{CD} 4^{+} \mathrm{T}$ cells. Histamine alone failed to induce the maturation of DCs, as shown by phenotypic analysis (Table 1); thus, histamine had no effect on the maturation marker CD83 or on CD40, although it did cause moderate but consistent increases in CD86, CD80, MHC II, and a slight decrease in MHC I. Small histamine-mediated effects on iDC phenotype have also been seen by others $(33,34)$. Incubation of iDCs

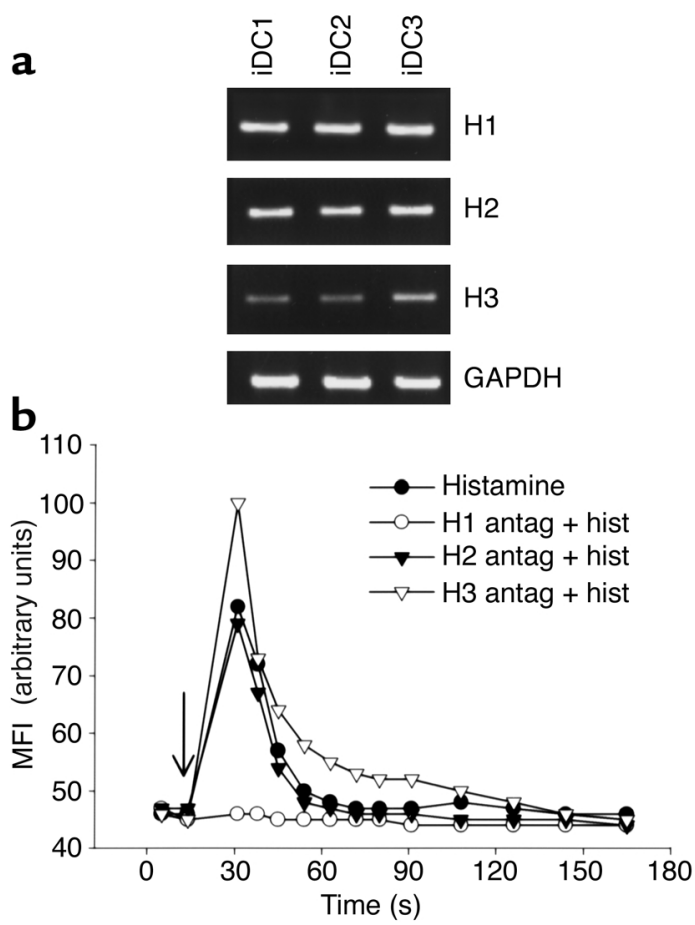

Figure 1

iDCs express three histamine receptors, and $\mathrm{H} 1$ is functionally active. (a) RT-PCR showing expression of histamine receptors $\mathrm{H} 1, \mathrm{H} 2$, and $\mathrm{H} 3$, and the GAPDH control in iDCs from three different donors. (b) Incubation of iDCs with histamine causes an increase in intracellular calcium that is blocked by an $\mathrm{H} 1$-specific antagonist. Fluo-3-loaded iDCs were preincubated at $0^{\circ} \mathrm{C}$ for 30 minutes with the indicated histamine receptor antagonist, warmed at $37^{\circ} \mathrm{C}$ for 1 minute, and at the time indicated by the arrow, stimulated with $10 \mu \mathrm{M}$ histamine. Similar data were obtained with iDCs from two other donors. Antag, antagonist; Hist, histamine; MFI, mean fluorescence intensity. 
a

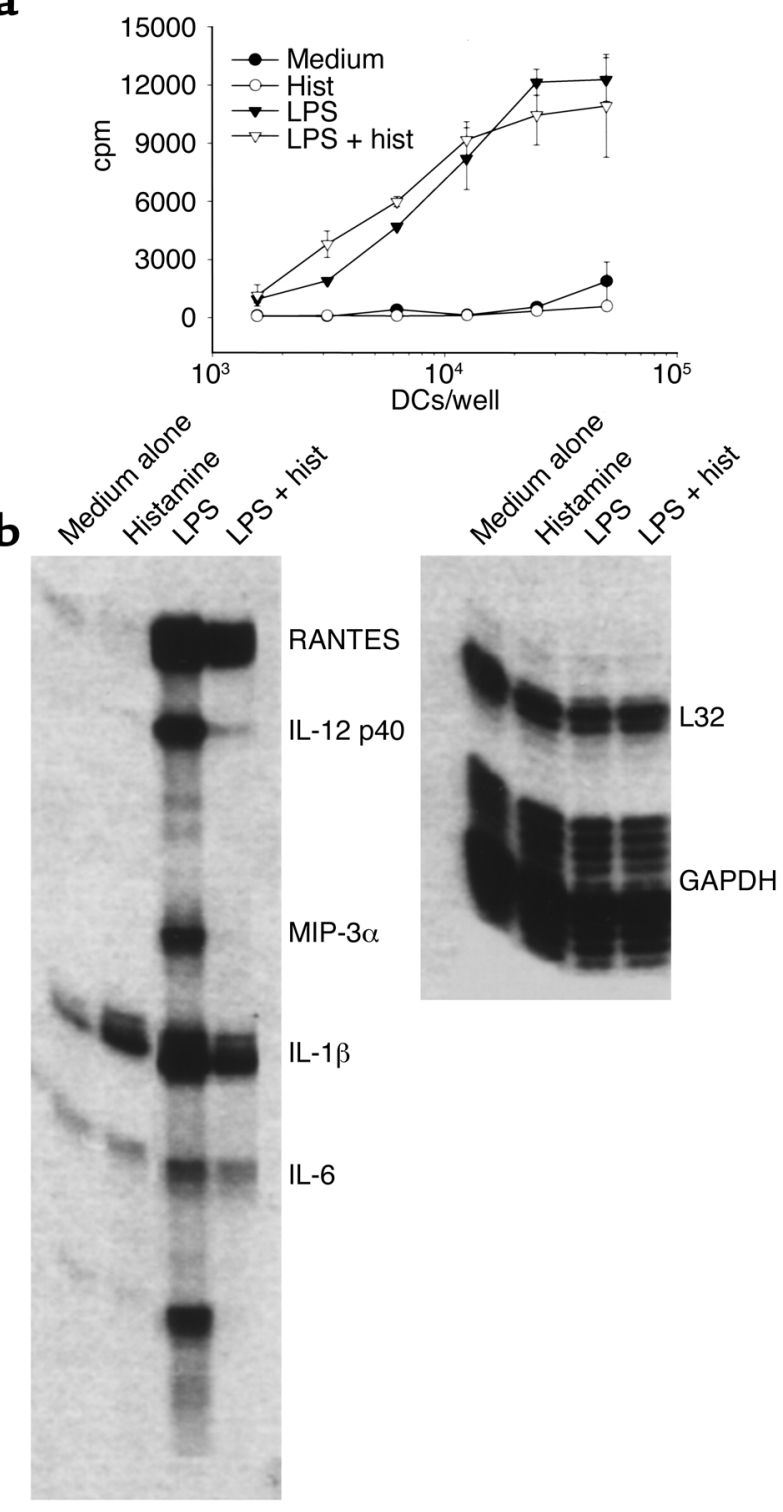

with LPS, a strong inducer of maturation, caused sharp increases in all markers tested, and the presence of histamine had little effect on these increases. Consistent with its inability to significantly alter the phenotype of DCs, histamine had little effect on the capacity of DCs to stimulate proliferation of allogeneic CD45RA ${ }^{+}$, $\mathrm{CD}^{+}$naive T cells. As shown in Figure 2a, DCs that had matured in cultures containing LPS plus histamine stimulated naive $T$ cells about as effectively as DCs that had matured in LPS alone. Moreover, iDCs incubated in medium alone failed to activate naive $\mathrm{T}$ cells, as expected, and treating iDCs with histamine in the absence of LPS did not confer stimulatory capacity. Finally, addition of anti-IL-10 (see below) to histamine-treated iDCs did not produce APCs that stimulated proliferation of naive T cells (data not shown).

Histamine alters the expression of cytokines and chemokines in maturing DCs. DC maturation is associated with increased synthesis of a number of cytokines that act

\section{Figure 2}

Histamine does not alter the APC function of DCs, but strongly regulates cytokine expression. (a) APC function. DCs were left untreated (medium alone), or were incubated overnight with histamine, LPS, or both (LPS + hist). Washed, irradiated DCs were added to allogeneic naive CD45RA ${ }^{+}$, $\mathrm{CD}^{+} \mathrm{T}$ cells, and $\mathrm{T}$ cell proliferation was assessed after 4 days by $\left[{ }^{3} \mathrm{H}\right]$ thymidine incorporation. One experiment of five performed is shown. (b) Cytokine and chemokine expression. iDCs were incubated with medium alone, or with medium containing histamine, LPS, or both. After 18 hours, total RNA was extracted and probed for cytokine/chemokine message expression using an RPA. Similar data were obtained in four separate experiments.

on T cells to induce a Th1 or Th2 phenotype. Since histamine failed to influence the phenotype and priming capacity of DCs, we asked whether it might affect cytokines produced by DCs. Accordingly, we performed a series of ELISAs and RPAs (one of which is shown in Figure 2b), using culture supernatants and RNA samples from DCs that had been matured with LPS in the presence or absence of histamine. The results of these studies, which are summarized in Table 2, indicate that histamine indeed greatly influences the expression of multiple cytokines and chemokines. Thus histamine either totally or partially blocked the LPS-mediated induction of IL-12 (both subunits, p35 and p40), IL- $1 \alpha$ and IL- $1 \beta$, IL-18, IL-6, IP-10, MIP-3 $\alpha$, and RANTES; by contrast, histamine increased the expression levels of IL-8 and IL- 10 .

Histamine inbibits IL-12 secretion in LPS-treated DCs via $H 2$ receptors. We next analyzed the mechanism of action of histamine on iDCs by focusing on IL-12, one of the cytokines affected by histamine. Figure 3a shows the production of IL-12 p70, the biologically active form of IL-12, in supernatants of DCs that had matured in culture medium containing LPS and increasing amounts of histamine. As seen, DCs that were treated with LPS alone released substantial amounts of IL-12. However, as the histamine concentration increased, IL-12 secretion decreased in a dosedependent way. In seven independent experiments, the addition of a saturating concentration of histamine $(10 \mu \mathrm{M})$ to LPS-stimulated iDCs inhibited secretion of

Table 1

Histamine induces minor changes in DC phenotype

\begin{tabular}{lcccccc}
\hline & CD83 & CD86 & CD80 & MHCI & MHC II & CD40 \\
Medium & 3 & $108(13)$ & 83 & 587 & 367 & 55 \\
Histamine & 3 & $157(55)$ & 147 & 437 & 481 & 54 \\
LPS & 67 & $167(94)$ & 235 & 673 & 757 & 164 \\
LPS + & 68 & $213(96)$ & 225 & 689 & 720 & 139
\end{tabular}

histamine

iDCs were left untreated (medium alone), or were treated with $10 \mu \mathrm{M}$ histamine, $100 \mathrm{ng} / \mathrm{ml}$ LPS, or both. After 18 hours, surface expression of selected markers was analyzed by flow cytometry. Data are presented as net mean channel fluorescence (mean fluorescence values of the total cell population minus the background fluorescence) for the entire population of cells, except for CD86, which is expressed as the net mean fluorescence of the positive peak (\% positive cells). Data are from one donor, representative of seven analyzed. 


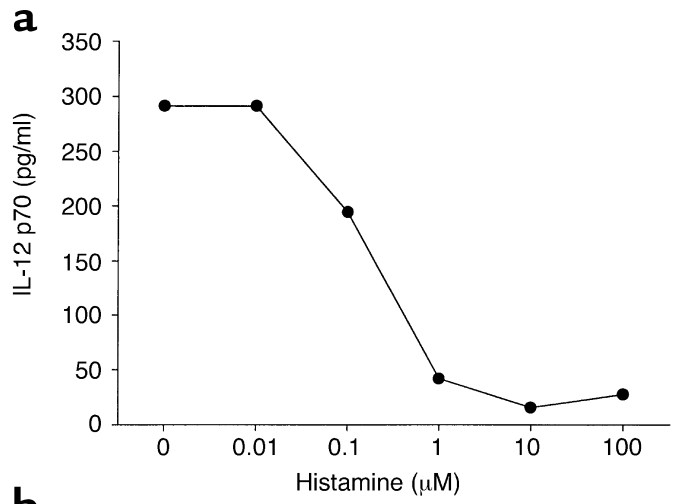

b
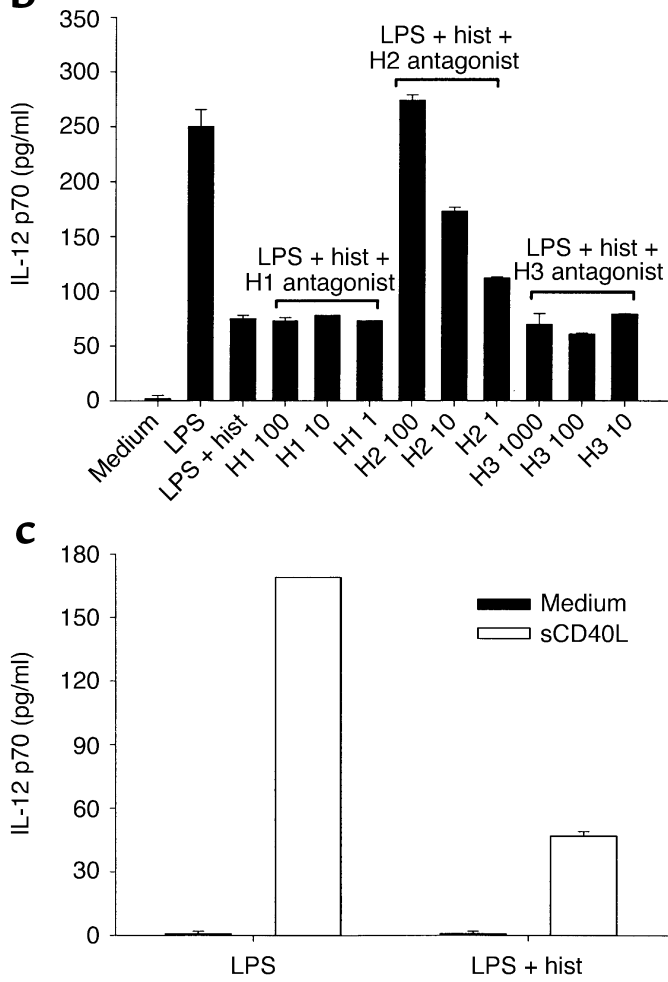

IL-12 by an average of $73 \% \pm 8 \%$ (range $50-95 \%$ ). To determine which histamine receptor was responsible for this effect, we preincubated DCs with histamine receptor antagonists at concentrations that spanned the published $\mathrm{IC}_{50}$ values for each of the three receptors, before adding LPS and histamine. Figure $3 \mathrm{~b}$ shows that the $\mathrm{H} 2$, but not the $\mathrm{H} 1$ or $\mathrm{H} 3$ antagonists, reversed the suppressive effect of histamine on IL-12 secretion, indicating that inhibition is mediated by the binding of histamine to H2. In addition, RPA analyses revealed that most, if not all, of the histamine-induced changes described in Table 2 were blocked by the $\mathrm{H} 2$ antagonist exclusively (data not shown). Therefore, the $\mathrm{H} 2$ receptor is not only expressed at the RNA level in iDCs (Figure1), but is also expressed as a functionally active receptor on their surface.

The IL-12 levels we detected in Figure 3, a and b, were derived from DCs that were undergoing maturation. During the priming of naive $\mathrm{T}$ cells by $\mathrm{mDCs}$ in the secondary lymphoid organs, engagement of CD40 on

\section{Figure 3}

Histamine inhibits the release of IL-12 p70 from LPS-matured DCs. (a) Dose-dependent inhibition of IL-12 secretion. iDCs were incubated with LPS in the presence of titrated amounts of histamine. Secreted IL-12 was measured by ELISA after 20 hours. Data are representative of three experiments performed. (b) Histamine inhibits IL-12 release via $\mathrm{H} 2$ receptors. iDCs were incubated with titrated amounts of histamine receptor antagonist, and after 1 hour, LPS and histamine were added. Cells were cultured for an additional 20 hours, after which supernatants were harvested and assayed for IL-12. The following histamine receptor antagonists were used: the $\mathrm{H} 1$ antagonist pyrilamine at 100, 10, and 1 $\mathrm{nM}$; the $\mathrm{H} 2$ antagonist cimetidine at 100,10 , and $1 \mu \mathrm{M}$; and the $\mathrm{H} 3$ antagonist thioperamide at 1,000,100, and $10 \mathrm{nM}$. Similar data were obtained in two other experiments. (c) The histamine-mediated inhibition of IL-12 secretion persists in CD40L-stimulated mDCs. DCs were matured with LPS alone, or LPS plus histamine for 18 hours. After washing, cells were stimulated for an additional 18 hours with either medium only or with soluble CD40L, and IL-12 levels were determined in supernatants. One of three experiments is shown.

mDCs is necessary for continued IL-12 release (35). We therefore asked whether mDCs, after removal of LPS and histamine, would remember the original maturation conditions when stimulated with CD40L. DCs were treated overnight with either LPS or LPS plus histamine, thoroughly washed, and then cultured with or without soluble CD40L for another 18 hours. As seen in Figure 3c, CD40 engagement induced high levels of IL-12 secretion from LPS-matured DCs, but cells that had been matured in LPS with histamine produced much lower amounts of IL- 12 .

IL-10-dependent and-independent processes inbibit IL-12 secretion. It is well established that IL-10 inhibits IL-12 secretion in monocytes and DCs (36). Since histamine and LPS together induce iDCs to secrete high amounts of IL-10 (Figure 4a), we asked whether IL-10 is involved in the suppression of IL-12 in histamine-treated DCs. iDCs were therefore treated for 18 hours with LPS in the presence or absence of histamine and/or anti-IL-10, and supernatants were analyzed for IL-12 content. Figure $4 \mathrm{~b}$ shows that the neutralization of IL-10 in cultures of LPS-treated iDCs, in the absence of histamine, induced a six- to sevenfold increase in IL-12, confirming a previous report on the regulatory role of IL-10 in iDCs under similar conditions (37). When cells were matured with LPS and saturating concentrations of histamine in the presence of the anti-IL-10 antibody, the levels of IL-12 were significantly decreased, indicating that histamine can regulate IL-12 secretion independently of IL-10. However, the inhibition of IL-12 was incomplete compared with cultures containing histamine but no anti-IL-10 (83\% vs. $96 \%$ inhibition, respectively, for the donor in Figure 4), suggesting that a portion of the histamine effect is IL-10-dependent.

Short-term treatment with histamine instructs iDCs to secrete low levels of IL-12. Within a few hours of receiving a maturation signal, iDCs leave peripheral tissues and migrate to the draining lymph nodes. Therefore, histamine must exert its effect on iDCs during the first few hours of the maturation process if it is to have 
Table 2

Histamine-dependent changes in mediator expression

$\begin{array}{lccccc}\text { Mediator } & \text { Method } & \text { Medium } & \text { Histamine } & \text { LPS } & \text { LPS + histamine } \\ \text { IL-1 } \alpha & \mathrm{R} & 0.52 & 0.74 & 2.53 & 1.56 \\ \text { IL-1 } \beta & \mathrm{R} & 0.15 & 0.50 & 2.95 & 1.19 \\ \text { IL-6 } & \mathrm{R} & 0.02 & 0.02 & 1.40 & 0.06 \\ \text { IL-8 } & \mathrm{R} & 0.04 & 0.25 & 1.93 & 2.66 \\ \text { IL-12 p35 } & \mathrm{R} & 0.01 & 0.02 & 0.38 & 0.03 \\ \text { IL-12 p40 } & \mathrm{R} & 0.01 & 0.02 & 2.51 & 0.21 \\ \text { IL-18 } & \mathrm{R} & 0.45 & 0.48 & 2.15 & 0.56 \\ \text { IP-10 } & \mathrm{R} & 0.02 & 0.08 & 1.16 & 0.06 \\ \text { MCP-1 } & \mathrm{R} & 0.00 & 0.01 & 0.08 & 0.02 \\ \text { MIP-3 } \alpha & \mathrm{R} & 0.00 & 0.00 & 1.38 & 0.05 \\ \text { RANTES } & \mathrm{R} & 0.04 & 0.04 & 5.45 & 4.43 \\ \text { IL-6 } & \mathrm{E} & 0 & 0 & 61.7 & 22.2 \\ \text { IL-8 } & \mathrm{E} & 0 & 0 & 9.4 & 23.0 \\ \text { IL-10 } & \mathrm{E} & 0.025 & 0.044 & 0.724 & 1.436 \\ \text { RANTES } & \mathrm{E} & 0 & 0 & 235 & 180\end{array}$

$A_{i}$ DCs were incubated in medium alone, or in medium containing LPS (100 $\mathrm{ng} / \mathrm{ml})$, histamine $(10 \mu \mathrm{M})$, or both. After 18 hours, RNA was extracted from cells and analyzed by RPA, and supernatants were harvested and assayed for mediator release by ELISA. Data were obtained using DC preparations from five different donors, and each entry is representative of at least two determinations. IL-4 was not detected by either method. For the RPA data, gels were scanned; indicated values represent ratios of intensities of each cytokine band to the L32 control. ELISA results are in $\mathrm{ng} / \mathrm{ml}$. ${ }^{\mathrm{B} T h e}$ LPS concentration was 1 $\mathrm{ng} / \mathrm{ml}$. At higher LPS concentrations, histamine induces a mild decrease in IL-8 expression. R, RPA. E, ELISA.

physiological relevance. To determine the length of time that iDCs must be in contact with histamine for IL-12 secretion to be downregulated in $\mathrm{mDCs}$, iDCs were treated with histamine plus LPS for 1,3 , or 6 hours, after which histamine was removed and replaced with medium containing LPS alone. After a total of 24 hours of incubation, supernatants were tested for IL-12 content. Controls included iDCs that had been incubated in medium alone, medium containing only LPS, and medium containing both LPS and histamine for the full 24 hours. Figure 5 shows that even a 1-hour treatment with histamine was sufficient to markedly decrease IL- 12 production, and that further decreases with time were minor. Thus, a short-term exposure to histamine during the early stages of maturation instructs iDCs to secrete low levels of IL-12 after they have reached the mature state. Altered polarization of naive T cells by histamine-treated $D C$ s. Because cytokines such as IL-10 and IL-12 determine the Th1-Th2 balance of responding $\mathrm{T}$ cells, we reasoned that histamine-treated DCs might polarize $T$ cells differently than would DCs matured in the

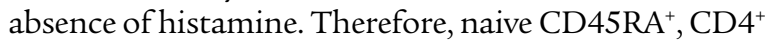
$T$ cells were stimulated with allogeneic DCs that had been matured with LPS in the presence or absence of histamine. Following stimulation and expansion in IL-2-containing medium, the patterns of IL-4 and IFN- $\gamma$ production by the DC-primed T cells were analyzed by internal staining and flow cytometry. FACS profiles from two representative donors are shown in Figure 6a. As seen, histamine treatment of DCs resulted in dramatic decreases in the percentages of
IFN- $\gamma$-positive T cells and increases in IL-4-positive cells. Despite considerable donor variability, especially in the percentages of IL-4-producing cells, this trend was consistent among the six donors tested (Figure 6b). Thus, by influencing the repertoire of cytokines secreted by DCs, histamine has the capacity to tilt primary $T$ cell responses toward a Th2 phenotype.

\section{Discussion}

Histamine is a major causative factor of atopic diseases such as allergy, asthma, anaphylaxis, and atopic dermatitis. In this report we show that histamine, by acting directly on iDCs, also has the capacity to influence the development of adaptive responses to antigen. We initially demonstrated that iDCs express at least two active histamine receptors, $\mathrm{H} 1$ and $\mathrm{H} 2$. Histamine alone did not induce the maturation of iDCs, nor did it significantly alter the phenotypes or priming capacities of DCs that had been matured by LPS stimulation. In contrast to its mild effects on iDCs in the absence of a maturation signal, histamine displayed a remarkable capacity for regulating the expression and secretion of a wide variety of cytokines and chemokines during LPS-driven maturation. Of special importance, hista-

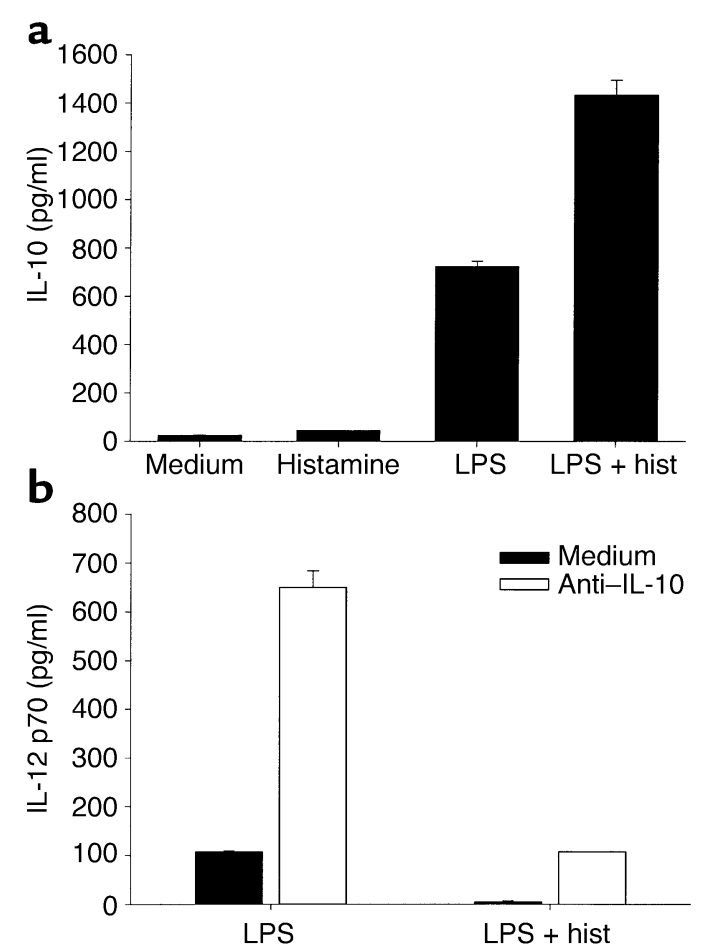

Figure 4

IL-10 is involved in the regulation of IL-12 by histamine. (a) Histamine and LPS induce IL-10 secretion additively. DCs were incubated for 18 hours in medium alone, or in medium containing histamine, LPS, or both, after which supernatants were assayed for IL-10 content by ELISA. Data are representative of three separate experiments. (b) IL-10 regulates IL-12 secretion. iDCs were treated with LPS or LPS plus histamine, either in medium alone or in the presence of a neutralizing anti-IL-10 antibody. IL-12 secretion was assayed in supernatants after an 18-hour stimulation. One donor representative of three tested is shown. 


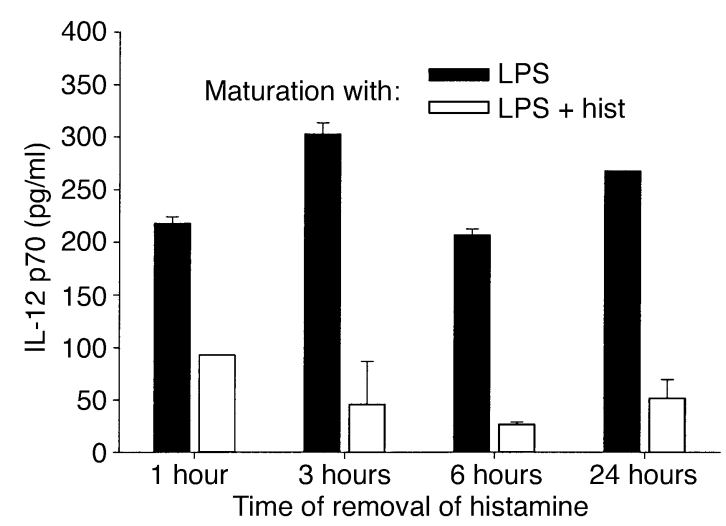

Figure 5

Short-term incubations with histamine suppress IL-12 production. iDCs were incubated with LPS in the presence or absence of histamine for the indicated periods of time, after which the cells were washed and replated with fresh medium containing LPS but no histamine. Secreted IL-12 was determined after a total of 24 hours. Similar results were obtained in two other experiments. The histamineinduced decrease was significant $(P<0.01)$ at all timepoints. $P$ values for DCs treated with LPS plus histamine: 0.12 ( 1 hour vs. 3 hours); $<0.001$ ( 1 hourvs. 6 hours); and 0.04 ( 1 hourvs. 24 hours).

mine, by acting on the $\mathrm{H} 2$ receptor during the initial phase of maturation, downregulated the production of IL-12 by mature DCs, a crucial cytokine for the development of Th1 responses. As expected from these results, DCs that had matured in the presence of histamine generated fewer Th1 cells and higher numbers of Th2 cells than did DCs that had matured in medium devoid of histamine.

Histamine regulates a large number of cytokines and chemokines in maturing DCs, certainly more than those listed in Table 2. Moreover, mast cells release a wide variety of physiologically active substances in addition to histamine, and it is possible that specific combinations of mediators would induce distinct repertoires of cytokines, allowing for fine-tuning of $\mathrm{T}$ cell responses. Of the cytokines affected by histamine treatment, IL-10, IL-12, and IL-18 have been implicated in T cell polarization. The downregulation of IL-12 and IL-18, both of which are strong promoters of Th1 development $(1,38)$, is undoubtedly a key element in the decreased generation of Th1 cells by histaminetreated DCs. The generation of Th2 cells is more difficult to explain. IL-4, a major inducer of Th2 cells, was not detected in our DC preparations at the message level, even after treatment with LPS and histamine. However, in some systems, the development of Th2 cells does not require APC-derived IL-4 $(5,39)$, and it has been postulated that in the absence of IL-12 and IL-4, Th2 cells arise from a default pathway (40). It is also possible that histamine tilts the $\mathrm{T}$ cell responses toward the Th2 phenotype by acting at the level of costimulatory molecules. CD86 (B7.2) is required for the development of Th2 responses $(16,41)$, and our data, in addition to previously published results (34), indicate that histamine alone, while failing to induce complete DC maturation, is able to upregulate expression of CD86 in DCs. Moreover, we found that the expression levels of CD86 in DCs matured in the presence of LPS and histamine were higher than in DCs matured in the absence of histamine, whereas the opposite trend was observed for CD80 (B7.1) (Table 1). Thus, histamine might induce a Th2 response by selectively upregulating the expression of CD86 in DCs that are undergoing maturation.

The modulation of IL-12 and other cytokines and chemokines by histamine was mediated by the $\mathrm{H} 2$ histamine receptor, a typical $\mathrm{G}$ protein-coupled receptor a
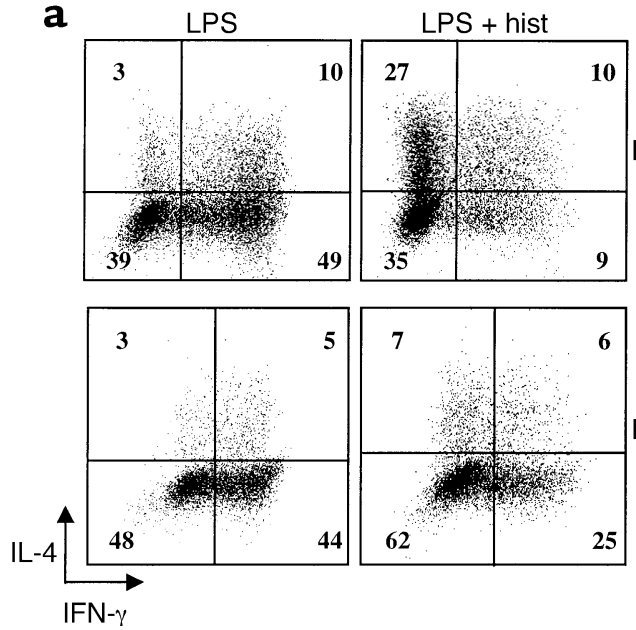

7

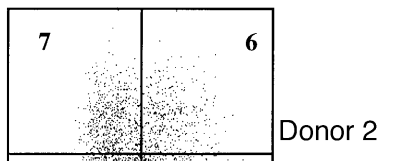

b

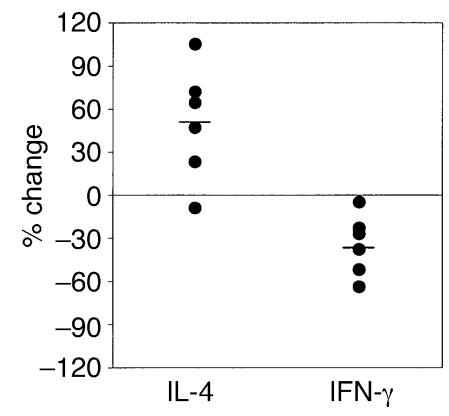

\section{Figure 6}

Histamine alters the polarizing capacities of DCs. (a) After an overnight incubation with LPS or LPS plus histamine, DCs were washed, irradiated, and added to allogeneic naive $C D 45 R A^{+}, C D 4^{+} T$ cells at a DC/T cell ratio of 1:10. T cells were primed, expanded, and internally stained for IFN- $\gamma$ and IL-4. Results from two experiments, using DCs and T cells from separate donors, are shown. (b) Six replicate experiments were performed using cells from different donors, and the percent changes in the IL-4- or IFN- $\gamma$-producing cells are shown for each. Average changes are indicated by the short horizontal lines. The average changes were significant using a Student $t$ test $(P=0.027$ for the increase in IL-4, and $P=0.01$ for the decrease in IFN- $\gamma$ ). 
containing seven transmembrane domains, that interacts with $\mathrm{G}_{\mathrm{s}}$ and activates adenylyl cyclase (26). A number of other agents, including cholera toxin, prostaglandin E2, $\beta 2$-agonists, and ATP inhibit IL-12 production in DCs via the G protein-adenylyl cyclase pathway $(14,15,23,42-48)$, and shift the Th balance of responding $T$ cells toward the Th2 phenotype (14, 44, 47). However, all these agents, with the exception of prostaglandin E2, are intrinsically able to induce full maturation of DCs, whereas histamine fails to do so. Indeed, the changes in phenotype and cytokine production in our DC preparations following histamine treatment were minimal, and did not generate APCs that were able to induce proliferation of naive $\mathrm{CD}^{+} \mathrm{T}$ cells. Histamine has dramatic effects on DCs and their T cell-polarizing capacities only if given concomitantly with LPS, or, presumably, other inflammatory agents. Therefore, despite the signaling through a cAMP-dependent pathway that is common to several other Th2-promoting mediators, histamine and prostaglandin $\mathrm{E} 2$ are unique in their requirement for a microbial priming signal to exert their effects.

An important aspect that further differentiates histamine from other cAMP-dependent, Th2-inducing agents is the mechanism by which it regulates IL-12 secretion. In fact, none of the mediators listed above has any effect on the production of IL-10, either when given alone or in combination with LPS, and they inhibit IL-12 secretion in an IL-10-independent fashion. In contrast, IL-10 expression is induced by either LPS or histamine alone, and together the two stimulators act additively, or perhaps synergistically (Figure $4 a)$; in addition, anti-IL-10 partially reversed the histamine-induced inhibition of IL-12 in LPS-treated DCs. However, the amount of IL-10 released by DCs treated with LPS plus histamine was not sufficient to inhibit DC maturation, as reported in other systems $(37,49)$. Finally, previous observations that histamine inhibits IL-12 secretion in a totally IL-10-independent manner in monocytes $(23,24)$ suggests that histamine regulates IL-12 secretion differently in monocyte-derived DCs than in the monocytes themselves. The positive stimulus for IL-12 expression occurs through TLR4, the signaling receptor for $\operatorname{LPS}(50,51)$. The recognition of LPS by TLR 4 initiates a cascade of serine and threonine kinases that results in the activation of NF- $\kappa B$ and several members of the MAP kinase family. Previous studies have shown that IL-10 blocks IL-12 expression by inhibiting NF- $\mathrm{KB}$ activation $(52,53)$; how the histamine/ $\mathrm{H} 2$ receptor, IL-10, and LPS/TLR4 pathways interact during the instructional phase of DC maturation to produce an appropriate repertoire of cytokines at the priming step remains unclear. The important aspect of the interactions between the LPS and histamine pathways for DC function is that a short-term treatment with histamine during LPS stimulation leads to an alteration of IL-12, and presumably other cytokines, many hours later. In vivo this would allow the DCs to receive instructional signals in the periphery and subsequently act upon them while priming $T$ cells in the lymphoid organs.

Since mast cells represent the main source of histamine in peripheral tissues, signals such as $\operatorname{IgE}$ crosslinking, or direct stimulation with pathogens that induce mast cell degranulation and histamine release, could profoundly influence the outcome of an immune response by programming the cytokineexpressing potential of neighboring iDCs. Upon receiving a maturation signal, such iDCs would migrate to the draining lymph nodes and present antigens to naive $T$ cells in the context of Th2-promoting cytokines. Since Th2 cells facilitate the production of IgE, the major mediator of histamine release when bound to FceRI on mast cells, the secretion of Th2-promoting cytokines by iDCs could establish a positive feedback loop that would contribute to the severity of the disease and explain the elevated levels of IgE and Th2 cells that are often observed in atopic patients (54).

\section{Acknowledgments}

We thank Alan Sher, Brian Kelsall, Pierre Henkart, and Gene Shearer for thoughtful suggestions during the preparation of this manuscript. We also thank Seth Steinberg for performing the statistical analysis shown in Figure 6b.

1. Mosmann, T.R., and Sad, S. 1996. The expanding universe of T-cell subsets: Th1, Th2 and more. Immunol. Today. 17:138-146.

2. Rescigno, M., Granucci, F., Citterio, S., Foti, M., and Ricciardi-Castagnoli, P. 1999. Coordinated events during bacteria-induced DC maturation. Immunol. Today. 20:200-203.

3. Banchereau, J., and Steinman, R.M. 1998. Dendritic cells and the control of immunity. Nature. 392:245-252.

4. Lanzavecchia, A., and Sallusto, F. 2001. The instructive role of dendritic cells on $\mathrm{T}$ cell responses: lineages, plasticity and kinetics. Curr. Opin. Immunol. 13:291-298.

5. Rissoan, M.C., et al. 1999. Reciprocal control of T helper cell and dendritic cell differentiation. Science. 283:1183-1186.

6. Pulendran, B., et al. 1999. Distinct dendritic cell subsets differentially regulate the class of immune response in vivo. Proc. Natl. Acad. Sci. USA. 96:1036-1041.

7. Maldonado-Lopez, R., et al. 1999. CD8alpha+ and CD8alpha- subclasses of dendritic cells direct the development of distinct $T$ helper cells in vivo. J. Exp. Med. 189:587-592.

8. Kalinski, P., Hilkens, C.M., Wierenga, E.A., and Kapsenberg, M.L. 1999. T-cell priming by type- 1 and type- 2 polarized dendritic cells: the concept of a third signal. Immunol. Today. 20:561-567.

9. Hilkens, C.M., Kalinski, P., de Boer, M., and Kapsenberg, M.L. 1997. Human dendritic cells require exogenous interleukin-12-inducing factors to direct the development of naive T-helper cells toward the Th1 phenotype. Blood. 90:1920-1926.

10. Vieira, P.L., de Jong, E.C., Wierenga, E.A., Kapsenberg, M.L., and Kalinski, P. 2000. Development of Th1-inducing capacity in myeloid dendritic cells requires environmental instruction. J. Immunol. 164:4507-4512.

11. Whittaker, D.S., Bahjat, K.S., Moldawer, L.L., and Clare-Salzler, M.J. 2000. Autoregulation of human monocyte-derived dendritic cell maturation and IL-12 production by cyclooxygenase-2-mediated prostanoid production. J. Immunol. 165:4298-4304.

12. Enk, A.H., Angeloni, V.L., Udey, M.C., and Katz, S.I. 1993. Inhibition of Langerhans cell antigen-presenting function by IL-10. A role for IL-10 in induction of tolerance. J. Immunol. 151:2390-2398.

13. De Smedt, T., et al. 1997. Effect of interleukin-10 on dendritic cell maturation and function. Eur. J. Immunol. 27:1229-1235.

14. Kalinski, P., Hilkens, C.M., Snijders, A., Snijdewint, F.G., and Kapsenberg, M.L. 1997. IL-12-deficient dendritic cells, generated in the presence of prostaglandin E2, promote type 2 cytokine production in maturing human naive T helper cells. J. Immunol. 159:28-35.

15. Kalinski, P., Schuitemaker, J.H., Hilkens, C.M., and Kapsenberg, M.L. 1998. Prostaglandin E2 induces the final maturation of IL-12-deficient 
CD1a+CD83+ dendritic cells: the levels of IL-12 are determined during the final dendritic cell maturation and are resistant to further modulation. J. Immunol. 161:2804-2809.

16. Kuchroo, V.K., et al. 1995. B7-1 and B7-2 costimulatory molecules activate differentially the Th1/Th2 developmental pathways: application to autoimmune disease therapy. Cell. 80:707-718

17. Hosken, N.A., Shibuya, K., Heath, A.W., Murphy, K.M., and O'Garra, A 1995. The effect of antigen dose on CD4+ T helper cell phenotype devel opment in a T cell receptor-alpha beta-transgenic model. J. Exp. Med. 182:1579-1584.

18. Iezzi, G., Scotet, E., Scheidegger, D., and Lanzavecchia, A. 1999. The interplay between the duration of TCR and cytokine signaling determines T cell polarization. Eur. J. Immunol. 29:4092-4101.

19. Langenkamp, A., Messi, M., Lanzavecchia, A., and Sallusto, F. 2000 Kinetics of dendritic cell activation: impact on priming of TH1, TH2 and nonpolarized T cells. Nat. Immunol. 1:311-316.

20. Mekori, Y.A., and Metcalfe, D.D. 2000. Mast cells in innate immunity. Immunol. Rev. 173:131-140.

21. Malaviya, R., Twesten, N.J., Ross, E.A., Abraham, S.N., and Pfeifer, J.D. 1996. Mast cells process bacterial Ags through a phagocytic route for class I MHC presentation to T cells. J. Immunol. 156:1490-1496.

22. Poncet, P., Arock, M., and David, B. 1999. MHC class II-dependent activation of CD4+ T cell hybridomas by human mast cells through superantigen presentation. J. Leukoc. Biol. 66:105-112.

23. van der Pouw Kraan T.C., et al. 1998. Histamine inhibits the production of interleukin-12 through interaction with $\mathrm{H} 2$ receptors. J. Clin. Invest. 102:1866-1873.

24. Elenkov, I.J., et al. 1998. Histamine potently suppresses human IL-12 and stimulates IL-10 production via $\mathrm{H} 2$ receptors. J. Immunol. 161:2586-2593.

25. Sallusto, F., and Lanzavecchia, A. 1994. Efficient presentation of soluble antigen by cultured human dendritic cells is maintained by granulocyte/macrophage colony- stimulating factor plus interleukin 4 and downregulated by tumor necrosis factor alpha. J. Exp. Med. 179:1109-1118.

26. Hill, S.J., et al. 1997. International Union of Pharmacology. XIII. Classification of histamine receptors. Pharmacol. Rev. 49:253-278.

27. Vandenberghe, P.A., and Ceuppens, J.L. 1990. Flow cytometric measurement of cytoplasmic free calcium in human peripheral blood $\mathrm{T}$ lymphocytes with fluo-3, a new fluorescent calcium indicator. J. Immunol. Methods. 127:197-205.

28. Visintin, A., et al. 2001. Regulation of Toll-like receptors in human monocytes and dendritic cells. J. Immunol. 166:249-255.

29. Jansen-Olesen, I., et al. 1997. Role of endothelium and nitric oxide in histamine-induced responses in human cranial arteries and detection of mRNA encoding H1- and H2-receptors by RT-PCR. Br. J. Pharmacol. 121:41-48.

30. Baroody, F.M., et al. 1999. Relationship between histamine and physiological changes during the early response to nasal antigen provocation. J. Appl. Physiol. 86:659-668.

31. Wenzel, S.E., Fowler, A.A., III, and Schwartz, L.B. 1988. Activation of pulmonary mast cells by bronchoalveolar allergen challenge. In vivo release of histamine and tryptase in atopic subjects with and without asthma. Am. Rev. Respir. Dis. 137:1002-1008.

32. Liu, M.C., et al. 1990. Evidence for elevated levels of histamine, prostaglandin $\mathrm{D} 2$, and other bronchoconstricting prostaglandins in the airways of subjects with mild asthma. Am. Rev. Respir. Dis. 142:126-132.

33. Szeberenyi, J.B., et al. 2001. Inhibition of effects of endogenously synthesized histamine disturbs in vitro human dendritic cell differentiation. Immunol. Lett. 76:175-182.
34. Caron, G., et al. 2001. Histamine induces CD86 expression and chemokine production by human immature dendritic cells. J. Immunol. 166:6000-6006

35. Schulz, O., et al. 2000. CD40 triggering of heterodimeric IL-12 p70 production by dendritic cells in vivo requires a microbial priming signal. Immunity. 13:453-462.

36. Moore, K.W., de Waal Malefyt, R., Coffman, R.L., and O'Garra, A. 2001. Interleukin-10 and the interleukin-10 receptor. Annu. Rev. Immunol. 19:683-765.

37. Corinti, S., Albanesi, C., la Sala, A., Pastore, S., and Girolomoni, G. 2001. Regulatory activity of autocrine IL-10 on dendritic cell functions. $J$. Immunol. 166:4312-4318.

38. Robinson, D., et al. 1997. IGIF does not drive Th1 development but synergizes with IL-12 for interferon-gamma production and activates IRAK and NFkappaB. Immunity. 7:571-581.

39. Schmitz, J., et al. 1994. Induction of interleukin 4 (IL-4) expression in T helper (Th) cells is not dependent on IL-4 from non-Th cells. J. Exp. Med. 179:1349-1353.

40. Moser, M., and Murphy, K.M. 2000. Dendritic cell regulation of TH1TH2 development. Nat. Immunol. 1:199-205.

41. Freeman, G.J., et al. 1995. B7-1 and B7-2 do not deliver identical costimulatory signals, since B7-2 but not B7-1 preferentially costimulates the initial production of IL-4. Immunity. 2:523-532.

42. van der Pouw Kraan, T.C., Boeije, L.C., Smeenk, R.J., Wijdenes, J., and Aarden, L.A. 1995. Prostaglandin-E2 is a potent inhibitor of human interleukin 12 production. J. Exp. Med. 181:775-779.

43. Braun, M.C., He, J., Wu, C.Y., and Kelsall, B.L. 1999. Cholera toxin suppresses interleukin (IL)-12 production and IL-12 receptor beta1 and beta2 chain expression. J. Exp. Med. 189:541-552.

44. Gagliardi, M.C., et al. 2000. Cholera toxin induces maturation of human dendritic cells and licences them for Th2 priming. Eur. J. Immunol. 30:2394-2403

45. Kalinski, P., Vieira, P.L., Schuitemaker, J.H., de Jong, E.C., and Kapsenberg, M.L. 2001. Prostaglandin $\mathrm{E}(2)$ is a selective inducer of interleukin$12 \mathrm{p} 40$ (IL-12p40) production and an inhibitor of bioactive IL-12p70 heterodimer. Blood. 97:3466-3469.

46. Panina-Bordignon, P., et al. 1997. Beta2-agonists prevent Th1 development by selective inhibition of interleukin 12. J. Clin. Invest. 100:1513-1519.

47. la Sala, A., et al. 2001. Extracellular ATP induces a distorted maturation of dendritic cells and inhibits their capacity to initiate Th1 responses. J. Immunol. 166:1611-1617.

48. Braun, M.C., and Kelsall, B.L. 2001. Regulation of interleukin-12 production by G-protein-coupled receptors. Microbes Infect. 3:99-107.

49. Morel, A.S., Quaratino, S., Douek, D.C., and Londei, M. 1997. Split activity of interleukin-10 on antigen capture and antigen presentation by human dendritic cells: definition of a maturative step. Eur. J. Immunol. 27:26-34.

50. Aderem, A., and Ulevitch, R.J. 2000. Toll-like receptors in the induction of the innate immune response. Nature. 406:782-787.

51. Wagner, H. 2001. Toll meets bacterial CpG-DNA. Immunity. 14:499-502.

52. Wang, P., Wu, P., Siegel, M.I., Egan, R.W., and Billah, M.M. 1995. Interleukin (IL)-10 inhibits nuclear factor kappa B (NF kappa B) activation in human monocytes. IL-10 and IL-4 suppress cytokine synthesis by different mechanisms. J. Biol. Chem. 270:9558-9563.

53. Schottelius, A.J., Mayo, M.W., Sartor, R.B., and Baldwin, A.S., Jr. 1999 Interleukin-10 signaling blocks inhibitor of kappaB kinase activity and nuclear factor kappaB DNA binding. J. Biol. Chem. 274:31868-31874.

54. Kay, A.B. 2001. Allergy and allergic diseases. First of two parts. N. Engl. J. Med 344:30-37. 